\title{
Socioeconomic Factors in Access to Renal Transplantation
}

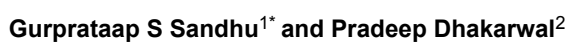

${ }^{1}$ Department of Medicine, University of Pittsburgh Medical Center, Pittsburgh, USA

${ }^{2}$ Division of Nephrology, University of Pittsburgh Medical Center, Pittsburgh, USA

"Corresponding author: Gurprataap S Sandhu, Department of Medicine, University of Pittsburgh Medical Center, 5230 Centre Ave, Pittsburgh, PA 15232, USA, Tel: 412-689-4446; E-mail: sandhugs@upmc.edu

Received Date: January 23, 2017; Accepted Date: February 26, 2017; Published Date: February 28, 2017

Copyright: (C) 2017 Sandhu GS, et al. This is an open-access article distributed under the terms of the Creative Commons Attribution License, which permits unrestricted use, distribution, and reproduction in any medium, provided the original author and source are credited.

\section{Abstract}

Background: Traditional socio-economic status (SES) factors that have been associated with access to renal transplantation include race, gender and income. However, these traditional factors are neither specific nor sensitive for 'at risk' status. There are now new and comprehensive SES assessment tools like the Social adaptability index (SAI) that provide an accurate and reliable estimate of an individual's social adaptability, and have been shown to predict graft failure and access to renal transplantation.

Summary: In this review we describe the various SES factors that have been shown to be associated with graft failure and access to renal transplantation. We also describe novel methods to quantify SES like the SAI. We also discuss, based on literature review, potential interventions to improve access to renal transplantation in individuals with lower SES.

Conclusion: There are several SES factors associated with access to renal transplantation. Quantifying SES through tools like SAI can aid in identifying at risk patients, and thereby, can assist in targeting interventions towards patients most likely to benefit from them and reducing disparities in access to renal transplantation.

Keywords: Socio-economic; Transplantation; Renal; Access

\section{Introduction}

Traditionally, disparities in access to renal transplantation have been described extensively in terms of race, gender, income and geographic location [1-4]. End-stage renal disease (ESRD) is known to be a major cause of morbidity and mortality in the United States and worldwide [5]. Furthermore, when compared with dialysis, kidney transplantation has been shown to be more cost effective and associated with longer survival and superior quality of life; and it is considered the treatment of choice for patients with ESRD [6]. When comparing clinical outcomes, different studies have estimated either graft or recipient survival when measuring kidney transplant outcome. For access to kidney transplantation, time between ESRD to wait-listing and/or time between wait-listing to actual transplant is usually estimated. Any intervention that is aimed to reduce disparities in access to healthcare or clinical outcomes, for it to be successful and cost-effective, it is vital to accurately identify the individuals most likely to benefit from that particular intervention, so that limited health care resources are utilized optimally. However, traditional factors known to be associated with renal transplantation outcome or access like race and gender are not sufficient to accurately identify if an individual patient is at risk for inferior clinical outcomes. In this review, we discuss the various SES factors that have been shown to be associated with graft failure and access to renal transplantation. In addition, we describe novel tools like the social adaptability index (SAI), which have been developed to provide more accurate and reliable information about the 'at risk' status of an individual patient. The SAI is unique as it does not depend on group characteristics like gender or race, and has been validated in several different studies in varied clinical outcomes.

\section{Known Disparities in Access to Renal Transplant}

Pre-transplant evaluation is one of the most crucial aspects of the transplant evaluation process. It underscores the significance of evaluating a patient's transplant candidacy based on objective medical criteria. However, several previous studies have demonstrated that African Americans [1-4], elderly [7], and women [8] are less likely to receive a renal transplant. The disparities that exist for African Americans have been extensively documented; however, studies have also shown that Hispanics, Asians and Native Americans also have reduced access to renal transplantation [9-12]. There also exists a difference in listing practices for transplant among different transplant centers $[13,14]$.

In addition to the factors listed above, there are several other socioeconomic factors that have been previously described to be associated with access to renal transplantation. Our group has previously demonstrated that patients, who are married or divorced/ separated, when compared to patients who are never married, have higher access to renal transplantation, specifically in the age group 40-65 [15]. This effect of higher access persisted for married patients in terms of receiving a transplant even after getting wait-listed. In addition, the results were consistent across most of the subgroups studied. Furthermore, it has been shown that being married has a positive effect on the graft survival (but not overall survival) [16]. Studies have previously shown that marital status can be associated with positive outcomes, including objective clinical outcomes [17]. Conversely, it has also been shown that transplantation itself might affect marital relationships $[18,19]$. The significant impact of marital status on access to renal transplantation could potentially be mediated by several factors including higher indulgence in substance abuse in unmarried individual, lower access to health care and living donors, 
inferior or absent health insurance, poor social network, lower income, and mental health issues like depression and anxiety.

Previously, we have also shown that indulging in substance abuse leads to reduced access to renal transplantation [20]. Polysubstance abuse has been associated with a reduction in the likelihood of being wait-listed for renal transplantation and receiving a kidney transplant. Predicted graft and recipient survival are important elements of the decision-making process in a pre-transplant evaluation. There exists a reasonable concern among transplant professionals that a recipient's substance abuse might be associated with and can lead to accelerated graft loss [21-24], because of changes in body physiology and patient noncompliance. As a result, many transplant programs listing and transplant criteria exclude patients who are actively involved in substance abuse. Indeed, recipient's active smoking status before transplant has been shown to be associated with allograft loss [21].

Now the question is, based on the above, would it be reasonable to exclude all patients who are active smokers, abuse alcohol or drugs from being considered for renal transplant? To address this issue, we have previously calculated a "utility cost" if patients with substance abuse issues were transplanted at an equal rate to those with no substance abuse. As per our estimate, it would equate an additional renal allograft loss of $0.34 \%$ [20]. We believe that clinicians need to find a more optimal middle ground, where decisions regarding exclusion of patients from transplant are based on severity (e.g., possibly excluding patients with more than 25 pack years of smoking [22]) and type (e.g., patients with moderate alcohol consumption perhaps need not be excluded [25]) of substance abuse and assessment of compliance by pre-transplant psychological evaluation of the patient.

In addition, being unemployed has also been shown to be associated with reduced access to renal transplantation. We have previously shown that compared with unemployed patients, patients who are retired/disabled or working part time or full time are more likely to be placed on the waiting list for renal transplantation and once on the list are more likely to receive a transplant [26]. We observed a smaller effect size for transplant compared with listing/transplant which could potentially be explained by the fact that the patients who are already wait-listed represent a more homogenous sample. And indeed, patients may get inactivated after being listed based on their health status; however, value-laden judgment is minimized once the patients are on the waiting list.

The reported disparities for unemployed patients are likely caused by a combination of factors that have to do with the transplant program or with the patients themselves. There are several potential factors that might contribute towards transplant programs unwillingness to list and transplant poorly employed candidates. Firstly, one of the primary concerns of transplant centers is the recipient's ability to afford immunosuppressive medications posttransplant. The ability to procure immunosuppressive medications, patient's employment status, and expected graft and patient survival after transplant are all linked phenomenon. Lack of employment can lead to limited financial resources for the patient and subsequent inadequate health care. This can lead to late referrals by nephrologists and delayed evaluation by transplant centers. Furthermore, lack of financial resources (which may be in part due to underemployment) may also be associated with patient's non-compliance, which is the third leading cause of renal allograft loss after rejection and infection [27], and remains a significant cause of patient mortality [28]. While many factors may lead to non-compliance after transplant, incapacity to pay for expensive immunosuppressive medications might be perceived as barrier by a transplant program. The second potential mechanism has to do with insurance status, traditionally inferior in poorly employed individuals. Specifically, being employed allows patients to access employer group health insurance. A majority of the population with health insurance coverage in the United States obtains it through their employment [29]. There is evidence to suggest that lack of insurance can significantly contribute toward non-compliance and might be responsible for up to $35 \%$ of renal allograft loss [28,30-32].

Another socioeconomic factor that has been consistently shown to be associated with access to renal transplantation is recipient's education level. Similar to biologic factors, most of the socioeconomic factors are not easily modifiable. Education level is unique in this regards, as it might be amenable to modification, even at a later stage in life, specifically health literacy. Theoretically, everyone in life should have an equal opportunity of learning, but that is often not the case. The relationship between education level and access to renal transplantation in subjects of different racial or ethnic backgrounds has been investigated in the past by our group. In a previous study we have shown that racial disparities (when comparing white and African American patients) do exist in access to renal transplantation, however, such racial disparity might not be present in highly educated African American patients [33]. In our study, with a sample size of 3224 patients with end-stage renal disease (ESRD), education data collected from United States Renal Data System (USRDS), when compared to white patients, the rate of college graduation was lower in African Americans (16.7\% vs. 10\%). Furthermore, a lower percentage of African Americans graduated from high school (30\% vs. $38.6 \%)$. We also found that African Americans were less likely to receive a transplant (hazard ratio of $0.7, \mathrm{p}<0.001$ for getting wait listed or transplanted without listing; and hazard ration of $0.58, \mathrm{p}<0.001$ for receiving a transplant post wait-listing). Moreover, patients of African American race were less likely to be either wait listed or receive a transplant in the three less educated group of ESRD patients: hazard ratio of $0.67(\mathrm{p}=0.005)$ in the never completed high school group, hazard ratio of $0.76(p=0.02)$ for the high school graduate group, and hazard ratio of $0.65(\mathrm{p}=0.003)$ for the partial college educated group. It is interesting to note that in the completed college educated group, the difference was not found to be statistically significant (hazard ratio of $0.75, \mathrm{p}=0.1$ ), suggesting that higher education can help reduce racial disparities.

\section{Novel Ways to Quantity and Estimate Individual Socioeconomic Status}

As previously mentioned, there are several socioeconomic factors that can affect access to renal transplantation, including sex, race, income and geographic location. However, it should be noted that identifying a specific individual as at risk, based on their race or sex lacks sensitivity and specificity, and can often be inaccurate. For example, a person who in an African American, but has high income and a college degree or high education level might not necessarily be at risk. To alleviate this issue, we developed a comprehensive, easy to calculate tool to assess an individual's socio-economic status called the Social Adaptability Index (SAI). SAI is calculated as a sum of five scores related to employment status, education level, marital status, substance abuse and income. To eliminate the problem of scalability in SAI, each individual component is graded on a scale of $0-3$ without 
additional weighting, so that each individual component contributes equally (from 0 to 3 points) to the final calculation of the SAI.

The grading system that has been used in several studies validating the SAI is as follows: 1) Employment status: 0=unemployed, not working due to medical conditions, or not working by choice; $1=$ retired; $2=$ working part time; $3=$ working full time. 2) Education level: $0=$ did not complete high school; 1 =graduated high school; $2=$ graduated college; $3=$ doctoral degree or any post college education. 3) Marital status: $0=$ not married (including never been married and widowed); $1=$ divorced or separated; $2=$ married without children; $3=$ married with children. In terms of defining the married category, it included individuals with partner in household, married with partner not living in the household, living as married or living with a partner. In addition, if there was data lacking for children, if the individual was married and the number of people in the household was $>2$, we considered that individual married with children (marital status $=3$ ); otherwise, we considered the individual married without children (marital status=2). 4) Substance abuse: $0=$ abusing all three substances, drugs, alcohol and tobacco; 1 =abusing two of above three substances; 2 = abusing one of above three substances; $3=$ not using any substances. Alcohol addiction was defined as present if any of the following criteria were met in the individual: (i) total number of days individuals used more than 9 drinks over the last 12 months was greater than 24; (ii) total number of days individuals used more than 4 drinks over the last 12 months was greater than 48; (iii) total number of days individuals used more than 1 drink over the last 12 months was greater than 240 . Drug addiction was defined based on marijuana or cocaine use history available in the dataset. In specific, drug addiction was defined as positive if the individual used marijuana or cocaine at least once over the last 30 days period. And finally, tobacco addiction was defined as positive if any of the following factors were true: (i) self-described as a smoker at the time of initial evaluation; (ii) the individual smoked cigarettes immediately prior to the evaluation (within $30 \mathrm{~min}$ ); (iii) number of cigarettes used in the past 5 days was greater than four. Finally the definition of income was variable in different studies and was primarily based on information available in that particular data set. In some studies, having health insurance was used a proxy for higher income level.

SAI has been shown to be associated with mortality in several different population subsets that include general American population [34], patients with diabetes mellitus [35], patients with chronic kidney disease [36], with end state renal disease (ESRD) [37], and those who had received a kidney transplant [38]. Higher SAI has also been shown to be associated with significant reduction in risk for graft loss and recipient mortality [38]. In addition, SAI has also been associated with parameters for access to health care, like access to renal transplantation. In a recent study, higher SAI was found to be associated with higher likelihood of being placed on the waiting list and receiving a transplant after being wait-listed [39]. SAI has been validated in multiple different populations as above, and is a reasonable quantifiable estimate on an individual patient's socioeconomic status. Various studies done with SAI and its association with different clinical outcomes in diverse populations are shown in Table 1. A conceptual model with underlying hypothesis and observed associations of SAI is described elsewhere [36].

Some of factors that lead to disparities in healthcare are likely not amenable to change at the healthcare provider or system level. However, a few interventions can be undertaken that might show clinical benefit. Specifically, education programs geared towards improving health literacy may improve the outcome in patients identified as at risk status based on low SAI scores [40]. In addition, navigation systems that streamline the process of transplant evaluation could potentially improve access to renal transplantation [41]. One might also consider incorporating an employment specialist into the healthcare team that evaluates a patient for transplantation, to provide vocational support pre and post-transplant. Ensuring continued employment can certainly aid in reducing disparities in access to healthcare and eventual clinical outcomes. Incorporation of care managers in to the transplant evaluation team can potentially assist the patients with self-management skills and willingness and commitment to make positive health behavioral changes [42].

\begin{tabular}{|l|l|l|l|}
\hline Patient population & Outcome & $\begin{array}{l}\text { Hazard } \\
\text { ratio }\end{array}$ & p value \\
\hline General US population [34] & Mortality & 0.87 & $<0.001$ \\
\hline Chronic kidney disease [36] & Mortality & 0.88 & $<0.001$ \\
\hline $\begin{array}{l}\text { End stage renal disease } \\
{[37]}\end{array}$ & Mortality & 0.97 & 0.006 \\
\hline Diabetes mellitus [35] & Mortality & 0.9 & $<0.001$ \\
\hline $\begin{array}{l}\text { End stage renal disease } \\
\text { [39] }\end{array}$ & $\begin{array}{l}\text { Renal transplant/wait- } \\
\text { listed }\end{array}$ & 1.19 & $<0.001$ \\
\hline $\begin{array}{l}\text { End stage renal disease } \\
\text { [39] }\end{array}$ & Renal transplant & 1.06 & $<0.001$ \\
\hline $\begin{array}{l}\text { Renal transplant patients } \\
\text { [38] }\end{array}$ & Graft loss & 0.89 & $<0.05$ \\
\hline $\begin{array}{l}\text { African American renal } \\
\text { transplant patients [43] }\end{array}$ & Acute rejection & 0.89 & $<0.05$ \\
\hline
\end{tabular}

Table 1: Association of the social adaptability index (SAI) with clinical outcomes in different studies.

\section{Conclusion}

To conclude, based on literature review, disparities do exist in access to renal transplantation, not only based on traditional at risk factors like female sex, African American race, rural location, but also based on other factors like being unemployed, marital status, active substance abuse, low income or education level. The intervention programs can identify at risk patients using novel SES assessment tools like the social adaptability index (SAI).

\section{Acknowledgements}

None of the authors of the manuscript have any conflict of interest to declare. The study was funded from the departmental funds and did not have any outside sponsor or funding agency. All authors had full access to all of the data in the study and take responsibility for the integrity of the data and the accuracy of the data analysis. The interpretation and reporting of these data are the responsibility of the authors and in no way should be seen as official policy or interpretation of the U.S. government.

\section{References}

1. Newmann J (1989) Patient race \& income, not dialysis unit profit status, affects transplant access. Nephrol News Issues. 
2. Bayat S, Frimat L, Thilly N, Loos C, Briancon S, et al. (2006) Medical and non-medical determinants of access to renal transplant waiting list in a French community-based network of care. Nephrol Dial Transplant 21: 2900-2907.

3. Epstein AM, Ayanian JZ, Keogh JH, Noonan SJ, Armistead N, et al (2000) Racial disparities in access to renal transplantation--clinically appropriate or due to underuse or overuse? N Engl J Med 343: 1537-1544

4. Eggers PW (1995) Racial differences in access to kidney transplantation. Health Care Financ Rev 17: 89-103.

5. United States renal data system (2016) Annual Data Report.

6. Rabbat CG, Thorpe KE, Russell JD, Churchill DN (2000) Comparison of mortality risk for dialysis patients and cadaveric first renal transplant recipients in Ontario, Canada. J Am Soc Nephrol 11: 917-922.

7. Oniscu GC, Schalkwijk AA, Johnson RJ, Brown H, Forsythe JL (2003) Equity of access to renal transplant waiting list and renal transplantation in Scotland: Cohort study. BMJ 327: 1261.

8. Garg PP, Furth SL, Fivush BA, Powe NR (2000) Impact of gender on access to the renal transplant waiting list for pediatric and adult patients. J Am Soc Nephrol 11: 958-964.

9. Hall YN, Choi AI, Xu P, O'Hare AM, Chertow GM (2011) Racial ethnic differences in rates and determinants of deceased donor kidney transplantation. J Am Soc Nephrol 22: 743-751.

10. Hall YN, O'Hare AM, Young BA, Boyko EJ, Chertow GM (2008) Neighbourhood poverty and kidney transplantation among US Asians and Pacific Islanders with end-stage renal disease. Am J Transplant 8: 2402-2409.

11. Hall YN, Sugihara JG, Go AS, Chertow GM (2005) Differential mortality and transplantation rates among Asians and Pacific Islanders with ESRD. J Am Soc Nephrol 16: 3711-3720.

12. Sequist TD, Narva AS, Stiles SK, Karp SK, Cass A, et al. (2004) Access to renal transplantation among American Indians and Hispanics. Am J Kidney Dis 44: 344-352.

13. Dudley CRK, Johnson RJ, Thomas HL, Rommel R, David A, et al. (2009) Factors That Influence Access to the National Renal Transplant Waiting List. Transplantation 88: 96-102.

14. Ramos EL, Kasiske BL, Alexander SR, Danovitch GM, Harmon WE, et al. (1994) The evaluation of candidates for renal transplantation: The current practice of U.S. transplant centers. Transplantation 57: 490-497.

15. Khattak MW, Sandhu GS, Woodward R, Stoff JS, Goldfarb-Rumyantzev AS (2010) Association of marital status with access to renal transplantation. Am J Transplant 10: 2624-2631.

16. Naiman N, Baird BC, Isaacs RB, Koford JK, Habib AN, et al. (2007) Role of pre-transplant marital status in renal transplant outcome. Clin transplant 21: 38-46.

17. Schoenborn CA (2004) Marital status and health: United States, 1999-2002. Adv Data, pp: 1-32.

18. Laederach-Hofmann K, Bunzel B, Freundorfer E, Schubert MT (2002) Changes in partner relationship after organ transplantation: Comparison between heart, liver, and kidney transplantation. Psychother Psychosom Med Psychol 52: 5-15.

19. Fathi-Ashtiani A, Karami GR, Einollahi B, Assari S, Aghanasiri F, et al. (2007) Marital quality in kidney transplant recipients: Easy to predict, hard to neglect. Transplant Proc 39: 1085-1087.

20. Sandhu GS, Khattak M, Woodward RS, Hanto DW, Pavlakis M, et al. (2011) Impact of substance abuse on access to renal transplantation. Transplantation 91: 86-93.

21. Sung RS, Althoen M, Howell TA, Ojo AO, Merion RM (2001) Excess risk of renal allograft loss associated with cigarette smoking. Transplantation 71: 1752-1757.

22. Kasiske BL, Klinger D (2000) Cigarette smoking in renal transplant recipients. J Am Soc Nephrol 11: 753-759.

23. Cosio FG, Falkenhain ME, Pesavento TE, Yim S, Alamir A, et al. (1999) Patient survival after renal transplantation: II. The impact of smoking. Clin Transplant 13: 336-341.
24. Woo YM, McLean D, Kavanagh D, Ward L, Aitken S, et al. (2002) The influence of pre-operative electrocardiographic abnormalities and cardiovascular risk factors on patient and graft survival following renal transplantation. J Nephrol 15: 380-386.

25. Fierz K, Steiger J, Denhaerynck K, Dobbels F, Bock A, et al. (2006) Prevalence, severity and correlates of alcohol use in adult renal transplant recipients. Clin Transplant 20: 171-178.

26. Sandhu GS, Khattak M, Pavlakis M, Woodward R, Hanto DW, et al. (2013) Recipient's unemployment restricts access to renal transplantation. Clin Transplant 27: 598-606.

27. Didlake RH, Dreyfus K, Kerman RH, Van Buren CT, Kahan BD (1988) Patient noncompliance: A major cause of late graft failure in cyclosporine-treated renal transplants. Transplant Proc 20: 63-69.

28. Hong JH, Sumrani N, Delaney V, Davis R, Dibenedetto A, et al. (1992) Causes of late renal allograft failure in the ciclosporin era. Nephron 62: 272-279.

29. Blakely S (2010) Employers, workers, and the future of employmentbased health benefits. EBRI Issue Brief 1-23.

30. Sanders CE, Curtis JJ, Julian BA, Gaston RS, Jones PA, et al. (1993) Tapering or discontinuing cyclosporine for financial reasons-a singlecenter experience. Am J Kidney Dis 21: 9-15.

31. Rovelli M, Palmeri D, Vossler E, Bartus S, Hull D, et al. (1989) Noncompliance in renal transplant recipients: Evaluation by socioeconomic groups. Transplant Proc 21: 3979-3981.

32. Schweizer RT, Rovelli M, Palmeri D, Vossler E, Hull D, et al. (1990) Noncompliance in organ transplant recipients. Transplantation 49: 374-377.

33. Goldfarb-Rumyantzev AS, Sandhu GS, Baird B, Barenbaum A, Yoon JH, et al. (2012) Effect of education on racial disparities in access to kidney transplantation. Clin Transplant 26: 74-81.

34. Goldfarb-Rumyantzev A, Barenbaum A, Rodrigue J, Rout P, Isaacs R, et al. (2011) New social adaptability index predicts overall mortality. Arch Med Sci 7: 720-727.

35. Goldfarb-Rumyantzev AS, Rout P, Sandhu GS, Barenbaum A, Patibandla BK, et al. (2012) Social adaptability index predicts overall mortality in patients with diabetes. J Diabetes Complications 26: 44-49.

36. Goldfarb-Rumyantzev AS, Rout P, Sandhu GS, Khattak M, Tang H, et al. (2010)Association between social adaptability index and survival of patients with chronic kidney disease. Nephrol Dial Transplant 25: 3672-3681.

37. Sandhu GS, Khattak M, Rout P, Williams ME, Gautam S, et al. (2011) Social Adaptability Index: Application and outcomes in a dialysis population. Nephrol Dial Transplant 26: 2667-2674.

38. Garg J, Karim M, Tang H, Sandhu GS, DeSilva R, et al. (2012) Social adaptability index predicts kidney transplant outcome: A single-center retrospective analysis. Nephrol Dial Transplant 27: 1239-1245.

39. Goldfarb-Rumyantzev AS, Sandhu GS, Baird BC, Khattak M, Barenbaum A, et al. (2011) Social Adaptability Index predicts access to kidney transplantation. Clin Transplant 25: 834-842.

40. Patzer RE, Perryman JP, Pastan S, Amaral S, Gazmararian JA, et al. (2012) Impact of a patient education program on disparities in kidney transplant evaluation. Clin J Am Soc Nephrol 7: 648-655.

41. Sullivan C, Leon JB, Sayre SS, Marbury M, Ivers M, et al. (2012) Impact of navigators on completion of steps in the kidney transplant process: A randomized, controlled trial. Clin J Am Soc Nephrol 7: 1639-1645.

42. Ciccone MM, Aquilino A, Cortese F, Scicchitano P, Sassara M, et al. (2010) Feasibility and effectiveness of a disease and care management model in the primary health care system for patients with heart failure and diabetes (Project Leonardo). Vasc Health Risk Manag 6: 297-305.

43. Taber DJ, Hamedi M, Rodrigue JR, Gebregziabher MG, Srinivas TR, et al. (2016) Quantifying the race stratified impact of socioeconomics on graft outcomes in kidney transplant recipients. Transplantation 100: 1550-1557. 